\title{
Medievalista
}

Online

$26 \mid 2019$

Número 26

Tese de doutoramento em História, apresentada à Universidade de

Santiago de Compostela, 2018. Orientação dos Professores Manuel

Núñez Rodríguez e David Chao Castro

\section{Espacios e Imágenes en el reino de Galicia (1075-1112). Persistencias y reforma.}

Tese de doutoramento em História, apresentada à Universidade de Santiago de Compostela, 2018. Orientação dos Professores Manuel Núñez Rodríguez e David Chao Castro

\section{Javier Castiñeiras López}

\section{OpenEdition}

\section{Journals}

Edición electrónica

URL: http://journals.openedition.org/medievalista/2730

DOI: $10.4000 /$ medievalista.2730

ISSN: 1646-740X

\section{Editor}

Instituto de Estudos Medievais - FCSH-UNL

\section{Edición impresa}

Fecha de publicación: 1 junio 2019

\section{Referencia electrónica}

Javier Castiñeiras López, «Espacios e Imágenes en el reino de Galicia (1075-1112). Persistencias y reforma. ». Medievalista [En línea], 26 | 2019, Publicado el 27 julio 2019, consultado el 23 septiembre 2020. URL : http://journals.openedition.org/medievalista/2730 ; DOI : https://doi.org/10.4000/ medievalista. 2730

\section{(c) (1) (5)}

Mediavalista está licenciado com uma Licença Creative Commons - Atribuição-NãoComercial 4.0 Internacional. 
Título / Title: Espacios e Imágenes en el reino de Galicia (1075-1112). Persistencias y reforma.

Tese de doutoramento em História, apresentada à Universidade de Santiago de Compostela, 2018. Orientação dos Professores Manuel Núñez Rodríguez e David Chao Castro

Autor(es) / Author(s): Javier Castiñeiras López

Afiliação institucional (Unidade de Investigação / Faculdade e Departamento, Universidade, Código postal, Cidade, País): Departamento de Patrimonio Artístico y Documental, Universidad de León, 24071, León, España

Email Institucional / Institutional email: jcasl@unileon.es

Fonte: Medievalista [Em linha]. Direc. Bernardo Vasconcelos e Sousa. Lisboa: IEM.

Disponível em:

http://www2.fcsh.unl.pt/iem/medievalista/MEDIEVALISTA26/lopez2612.html ISSN: 1646-740X

Data recepção do artigo / Received for publication: 27 de fevereiro de 2019 


\title{
$\sqrt[3]{n}$
}

\section{Espacios e Imágenes en el reino de Galicia (1075-1112). Persistencias y reforma}

\author{
Javier Castiñeiras López
}

Con el título Espacios e Imágenes en el reino de Galicia (1075-1112). Persistencias y reforma ${ }^{1}$, hemos desarrollado una tesis doctoral cuyo objetivo central fue el mejor conocimiento de los procesos de aparición del denominado lenguaje románico en el noroeste peninsular, específicamente en el territorio gallego durante el tránsito de los siglos XI al XII, a partir del estudio de las realidades plásticas y arquitectónicas en relación con los diferentes movimientos reformistas característicos del periodo.

La hipótesis de la que se partió fue que las modificaciones de los paradigmas artísticos y culturales que se suceden a partir del año mil no son mero fruto de un giro del gusto estético o el simple resultado de la recuperación de técnicas constructivas e ingenieriles de ascendencia romana, sino que, más bien, dichas transformaciones románicas pudieron nacer como respuesta a una serie de necesidades políticas, sociales y religiosas propias del tránsito de la Alta a la Plena Edad Media. Como veremos, de entre estas realidades un considerable número de investigadores ha puesto el foco en la importancia de las reformas político-religiosas del siglo XI como verdaderas generadoras del nuevo lenguaje figurativo y edilicio, $\mathrm{y}$, de entre estas, se ha ponderado como especialmente relevante la política del papado, conocida generalmente como Reforma Gregoriana. De Toubert a Barral, de Kitzinger a Pace, son varios los historiadores e historiadores del arte que han considerado y consideran el arte románico y su tiempo como parte de una dimensión cultural más amplia que las meras cuestiones de estilo.

\footnotetext{
${ }^{1}$ Por motivos de economía espacial reduciremos el aparato crítico al mínimo. Para un acercamiento más profundo al corpus bibliográfico empleado remitimos a nuestra tesis doctoral accesible a través del repositorio online Teseo. CASTIÑEIRAS LÓPEZ, Javier - Espacios e Imágenes en el reino de Galicia (1075-1112). Persistencias y reforma. Tesis Doctoral Inédita, Universidade de Santiago de Compostela: 2018.
} 
Bajo el binomio creado por los conceptos de "arte románico" y "reforma gregoriana" se engloba una amplia corriente historiográfica que defiende que la aparición del lenguaje románico debe ponerse en relación y es consecuencia directa de la política renovadora del papado reformado ${ }^{2}$. La idea de un arte de la reforma gregoriana nace a través de una serie de reflexiones en el seno de la comunidad científica acaecidas entre los años $60 \mathrm{y}$ 70 del pasado siglo ${ }^{3}$. Sin duda, fueron los trabajos de Ernst Kitzinger y Hélène Toubert los que consolidaron esta línea de trabajo para los historiadores del arte románico $\mathrm{y}^{4}$, en opinión de ambos, los agentes de los círculos papales actuaron como verdaderos ideólogos de las imágenes y a ellos se debería la profusión de determinados temas iconográficos (especialmente la recuperación de motivos iconográficos del primer cristianismo romano y la dignificación visual del oficio eclesiástico). De modo casi obligado, la mayor parte de los estudios de ambos investigadores se centraron en la Roma de los papas $^{5}$, si bien, sus estudios generaron una corriente de análisis que trascendió el análisis de las formas artísticas romanas para aplicar el método al conjunto de la geografía del arte románico ${ }^{6}$. Para finalizar este rápido repaso por los principales nombres vinculados a esta corriente de pensamiento historiográfico, se antoja obligatorio mencionar la amplísima producción del italiano A. C. Quintavalle, quien ha sido el verdadero referente de esta línea de pensamiento histórico en las últimas décadas ${ }^{7}$. El esfuerzo de sistematización de la teoría gregoriana de las artes realizada

\footnotetext{
${ }^{2}$ Sobre los preceptos generales de la reforma gregoriana véase FLITCHE, Augustine - La Réforme Grégorienne. 3 vol. Genève: Slatkine Reprints, 1978 [1924-1937]; TELLENBACH, Gerd - Church, State and Christian Society at the time of the Investiture Contest. Oxford: Basil Blackwell, 1966 [1959]; GUGGENHEIM, Sylvain - La Réforme Grégorienne. De la lutte pour le sacré à la secularisation du monde. Paris: Temps Présent, 2010.

${ }^{3}$ Podría señalarse como precedente a los estudios que pusieron el acento en el papel de la reforma cluniacense en el desarrollo del arte románico. WEISBACH, Werner - Religiöse Reform und mittelalterliche Kunst. Einsiedeln-Zürich: Verlagsanstalt Benziger and Co., 1945.

${ }^{4}$ KITZINGER, Ernst - "The Gregorian Reform and the visual arts: a problem of method". Transactions of the Royal Historical Society, vol. 22 (1972), pp. 87-102; TOUBERT, Hélène - Un art dirigé. Réforme grégorienne et Iconographie. Paris: Editions du Cerf, 1990.

${ }_{5}^{5}$ Resulta paradigmático el estudio del ciclo de frescos de la capilla de San Clemente en la actual capital italiana.

${ }^{6}$ Buena muestra de la internacionalización del método son los encuentros de la Université de Lausanne que han dado como fruto dos trabajos absolutamente referenciales ROMANO, Serena; ENCKELL, Julie (ed.) - Roma e la Riforma gregoriana: tradizioni e innovazioni artistiche (XI-XII secolo). Roma: I libri di Viella, 2007; FRANZÉ, Barbara (dir.) - Art et reforme grégorienne (XIe-XIIe siècles) en France et dans la péninsule Ibérique, Paris: Éditions A. et J. Picard, 2015.

${ }^{7} \mathrm{Su}$ producción en este sentido es muy copiosa e inabarcable para un trabajo de estas pretensiones. Remitimos nuevamente al texto completo de esta tesis doctoral. CASTIÑEIRAS LÓPEZ, Javier Espacios e Imágenes..., p. 54.
} 
por Quintavalle ha encontrado notables ecos en diversos trabajos que mantienen esta línea de estudio de plena actualidad ${ }^{8}$.

Por supuesto, la confección del binomio historiográfico arte románico/reforma gregoriana ha encontrado voces discrepantes y, de manera general, los detractores de la teoría gregoriana de las artes consideran que esta uniformiza y, hasta cierto punto simplifica, los procesos de creación culturales del periodo objeto de estudio, y que muchos de los temas y motivos del "arte gregoriano" son rastreables en cronologías anteriores y posteriores al proceso reformista ${ }^{9}$.

En los círculos académicos españoles la corriente historiográfica gregoriana no ha tenido el mismo peso que en otras tradiciones nacionales, si bien también existen algunos estudios importantes. Por su trascendencia (tanto nacional como internacional) deben destacarse los trabajos de M. A. Castiñeiras González, el ejemplo más claro de aplicación del método a la realidad artística hispana. Sus investigaciones sobre el arte románico gallego y sus relaciones con el universo gregoriano -con especial hincapié en la catedral de Santiago de Compostela en tiempos de Diego Gelmírez ${ }^{10}$ - hacen además de este autor un verdadero referente para el ámbito geográfico del que se ocupa esta investigación. La línea de trabajo expuesta mantiene su vigencia y son varias las publicaciones y proyectos de tesis doctorales que en los últimos años se han ocupado de uno u otro modo de la "cuestión gregoriana". Una excelente muestra de ello son los muy recientes trabajos de F. de Asís García García sobre la catedral de Jaca ${ }^{11}$.

Con este marco contextual realizamos nuestro estudio que, de una manera sintética, buscó dar respuesta (o al menos acercarnos a ella) a la siguiente pregunta: ¿es el primer

\footnotetext{
${ }^{8}$ Un notable ejemplo en esta línea se encuenta en KESSLER, Herbert Leon - "A Gregorian Reform Theory of Art?". in ROMANO, S.; ENCKELL, J. (ed.) - Roma e la Riforma gregoriana ..., pp. 25-48.

9 PACE, Valentino - "Roma e la Riforma gregoriana. Tradizioni e innovazioni artistiche (XI-XII secolo)". in ROMANO, Serena; ENCKELL Julie (ed.) - Roma e la Riforma gregoriana ..., pp. 49-59; BARRAL I ALTET, Xavier - Contre l'art roman? Essai sur un passé réinventé. Paris: Fayard, 2006.

${ }^{10}$ CASTIÑEIRAS GONZÁLEZ, Manuel Antonio - "Didacus Gelmirius, patrono de las artes. El largo camino de Compostela: de periferia a centro del Románico", in CASTIÑEIRAS GONZÁLEZ, Manuel Antonio - Compostela y Europa. La historia de Diego Gelmírez. Santiago de Compostela-Milán: Skira/S. A. de Xestión do Plan Xacobeo, 2010, pp. 32-97.

${ }^{11}$ GARCÍA GARCÍA, Francisco de Asís - Los portales de la catedral de Jaca. Reforma eclesiástica y poder real a finales del siglo XI. Huesca: Instituto de Estudios Altoaragoneses (Diputación de Huesca), 2018. Este trabajo ha sido publicado con posterioridad a la defensa de esta tesis doctoral por lo que no se encuentra reflejado en la bibliografía de la misma.
} 
arte románico de Galicia un ejemplo de lo que se ha venido dando en llamar un "arte reformado" o, por el contrario, estamos ante discursos espaciales y figurativos propios de una cultura conservadora y refractaria a los cambios?

Con el mismo espíritu elegimos el título de esta tesis -Espacios e imágenes en el reino de Galicia (1075-1112). Persistencias y reforma-, que busca expresar sucintamente los ejes fundamentales de nuestra investigación, tanto en lo cronológico como en lo geográfico y metodológico. De este modo, pretendimos que el título se vertebrase en función de cuatro motivaciones conceptuales diferentes: objeto de estudio (espacios e imágenes, o dicho de otro modo, arquitectura y artes figurativas), localización (reino de Galicia), cronología (1075-1112) y método (persistencias y reforma).

En cuanto al marco geográfico, consideramos pertinente utilizar el término "reino de Galicia" para referirnos al territorio en el que se llevaron a cabo las campañas artísticas estudiadas. No resulta sencillo emplear términos territoriales precisos en los estudios sobre el pasado, pues siempre se corre el riesgo de extrapolar conceptos netamente contemporáneos a las realidades geográficas medievales, con el consiguiente perjuicio para la corrección investigadora. En este caso nos hemos inclinado por el genérico término de "reino de Galicia", por ser esta una realidad nominal y conceptual presente en el siglo XI peninsular, como parece venir a mostrar -entre otras cuestiones- la decisión tomada por Fernando I de dividir su reino en tres diferentes y que cada uno de ellos fuera gobernado por uno de sus herederos: Castilla por Alfonso, León por Sancho y, finalmente, Galicia por García ${ }^{12}$.

A pesar de que este reino volvió a reunificarse con los de León y Castilla durante el inmediato gobierno de Alfonso VI, nos resulta un término más propicio que los de Galicia (demasiado vinculado quizá a la denominación de la actual comunidad autónoma) o de Gallaecia (asociado a una estructura territorial tardoantigua, aun cuando es cierto que es este un término que se siguió empleando durante toda la Alta y Plena Edad Media). En cualquier caso, entendemos los límites geográficos en un sentido de permeabilidad, y son constantes en este estudio las idas y venidas entre las realidades

12 Para el estudio del periodo véase REILLY, Bernard - El Reino de León y Castilla bajo el Rey Alfonso VI: 1065-1109. Toledo: Instituto Provincial de Investigaciones y Estudios Toledanos, 1989. 
noroccidentales y las de los principales centros político-culturales de los reinos cristianos peninsulares y del otro lado de los Pirineos. No sería posible de otro modo ofrecer un análisis de dinámicas culturales muy amplias, que se pretende objetivo, a partir únicamente de fenómenos exclusivamente locales. En esta misma línea, no analizamos el objeto artístico solo con relación a su contemporaneidad, sino que tendremos muy en cuenta la vigencia futura de muchas de sus soluciones $y$, especialmente, el diálogo entre estas últimas y los diferentes periodos artísticos del pasado inmediato.

Por su parte, hemos elegido una horquilla temporal que va desde el año 1075 al 1112 porque ambas fechas se corresponden con hitos fundamentales para el arte del periodo: en el año 1075 se toma la decisión de iniciar la construcción de un nuevo santuario en Santiago de Compostela ${ }^{13}$, que viniese a sustituir la vieja basílica de Alfonso III que, a la sazón, sería definitivamente demolida en el año 1112, como consecuencia directa de los avances de las obras de la fábrica románica. Entre ambos años, además, se produce en Galicia un impulso renovador del paisaje monumental con la utilización de un nuevo lenguaje edilicio, que la historiografía ha dado en llamar "arte románico", y que convencionalmente se ha venido a considerar como el primer lenguaje artístico "paneuropeo" desde la denominada "caída” del Imperio Romano de occidente.

Una vez establecidas las coordenadas cronológicas y geográficas constatamos que el número de vestigios de este periodo del románico inicial en Galicia es ciertamente reducido. Del mismo, únicamente conservamos cinco fábricas, y todas ellas de manera parcial; nos referimos a la catedral de Santiago de Compostela en sus primeras fases, San Antolín de Toques, San Xoán de Vilanova, San Bartolomé de Rebordáns y San Martiño de Mondoñedo ${ }^{14}$. Estos dos últimos edificios fueron a los que nos dedicamos de una manera más pormenorizada por dos motivos fundamentales:

\footnotetext{
${ }^{13}$ La polémica sobre el año de inicio de la catedral compostelana es recurrente y las fechas propuestas basculan entre el año 1075 y el año 1078, en cualquier caso parece claro que en el 1075 se toma la decisión de iniciar una nueva fábrica, iniciándose o no la obra en ese mismo año. Prescindimos deliberadamente de extendernos en este punto por motivos de espacio.

${ }^{14}$ Para un acercamiento a las fábricas románicas de estos edificios véase YZQUIERDO PERRÍN, Ramón - Galicia. Arte Medieval (I), tomo X. A Coruña: Hércules, D. L., 1993; GARCÍA GUINEA, Miguel Ángel, et alii (dir.) - Enciclopedia del Románico en Galicia. Aguilar de Campoo: Santa María la Real Fundación, 2012-2018.
} 
1. Las fábricas de Toques y Vilanova son testimoniales en cuanto a sus vestigios conservados.

2. La tradición crítica sobre las fases iniciales de la iglesia de Compostela (sin duda la campaña más referencial del periodo estudiado) es sumamente abundante, más si cabe desde el inicio de la década de los años 2000, lo que nos ha llevado a centrarnos en aquellos ejemplos menos estudiados.

En consecuencia, entendemos que por la importancia de los vestigios románicos conservados y por la ausencia de estudios sistemáticos desde planteamientos metodológicos no estrictamente formalistas, las iglesias de San Martiño de Mondoñedo y San Bartolomé de Rebordáns debían ocupar el centro de nuestro estudio. Ello no significa que no tengamos en cuenta las otras realidades monumentales gallegas, y así por un lado Toques y Vilanova tienen un capítulo propio, mientras que Compostela ha sido siempre tenida en cuenta en su condición de principal motor de creación artística de su época que, irremediablemente, hubo de condicionar las dinámicas culturales de su tiempo. Además, siendo definido el arte románico como el primer "arte unitario europeo" desde la caída de Roma, tampoco hemos obviado las grandes campañas que se estaban produciendo fuera de la geografía escogida: de Roma a Montecassino pasando por Conques y Toulouse, y León o Jaca, entre otras empresas artísticas de la época.

Una vez definido el objeto de estudio, a la hora de abordarlo hemos tomado una decisión metodológica, quizá cuestionable, basada en la separación de arquitectura y escultura. Somos plenamente conscientes de que dicha determinación supone un "falseamiento" del objeto artístico y que, especialmente en la Edad Media, las artes figurativas y los espacios arquitectónicos son un todo indisociable. A pesar de ello, entendemos que de cara a cotejar dichas empresas con la hipótesis de un arte gregoriano, resulta mucho más esclarecedor y ordenado un análisis por separado de sus elementos espaciales y de su imaginario. De cualquier manera, este condicionante organizativo se ha querido subsanar por medio de unas lecturas conclusivas que se han propuesto comprendiendo a espacios e imágenes como una única entidad, principio este que verdaderamente se ha mantenido presente en todo momento. 
La metodología empleada tanto para el estudio de los espacios como de las imágenes románicas de Mondoñedo y Rebordáns ha pretendido ser plural y por ello hemos atendido tanto a criterios de análisis formalistas como de corte iconográfico. Además, resultó fundamental la ayuda que nos ha proporcionado la arqueología a la hora de establecer nuevas hipótesis de datación, del mismo modo que el estudio de las informaciones sobre las modificaciones de las fábricas en cronologías no medievales ha permitido establecer algunas dudas razonables sobre la visión actual de ambas construcciones en relación con su imagen en el medievo.

Junto a este método esencialmente histórico artístico (irremediablemente parte central del trabajo) el estudio de los procesos políticos y religiosos ha sido el segundo gran eje metodológico en el que se ha sustentado esta tesis. De manera obligada en una investigación que pretende dilucidar las influencias (o la ausencia de las mismas) de la reforma gregoriana en el desarrollo del románico del noroeste peninsular, nos hemos detenido pormenorizadamente en aquellos posibles hitos de la política reformista papal en el territorio estudiado. Sin duda, son muchos los aspectos que se pudieran traer a colación, especialmente en una horquilla cronológica como la escogida, caracterizada por una cierta precipitación de acontecimientos, pero hemos querido destacar aquellos aspectos de la vida social, cultural, religiosa y política que a nuestro parecer habrían podido tener una mayor impronta en los discursos estéticos.

Como consecuencia de este proceso investigador decidimos realizar un trabajo organizado en cuatro grandes bloques o estructuras temáticas, con las que hemos pretendido otorgar al estudio de un sistema coherente en relación con las grandes líneas temáticas expresadas en el título.

El bloque I se encuentra organizado por medio de un capítulo introductoriometodológico inicial, seguido de otro sobre el contexto político-religioso del noroeste peninsular en el último cuarto del siglo XI. Un tercer subcapítulo se centra en el marco historiográfico en el que queremos encuadrar nuestra investigación y, finalmente, la última de estas subdivisiones es de tipo descriptivo acerca del estado actual de las dos iglesias objeto de estudio 
En este primer bloque, los dos capítulos intermedios tienen un espíritu de tipo contextual sustentado en dos ejes temáticos fundamentales: los procesos de introducción de las políticas reformistas (con especial atención en las reformas auspiciadas por Roma y Cluny) en los reinos cristianos peninsulares occidentales ${ }^{15}$, y la creación y desarrollo de una teoría de las artes basada en la relación del arte románico con el fenómeno gregoriano y su posible aplicación a las dinámicas culturales del marco geográfico a analizar.

De manera muy especial, en este apartado hemos considerado fundamental para una mayor comprensión de la huella gregoriana el estudio de la rica actividad conciliar fruto de la cual se suprimió el rito de tradición hispana y se produjo una reorganización diocesana que en el noroeste tuvo su máxima expresión en la restitución de la sede bracarense. Junto a estos aires renovadores, también tuvimos presente aquellos conatos de resistencia al cambio que se dieron en la península (el mundo monacal riojano es un buen ejemplo de ello) junto con aquellos eventos que pudieron ayudar a florecer una cierta neovisigotización cultural y política, como son la conquista de Toledo de $1085 \mathrm{o}$ la llegada de las reliquias de San Isidoro desde Sevilla a León en tiempos del monarca Fernando I.

Los bloques II y III son el verdadero núcleo de este estudio, en los que analizamos pormenorizadamente las iglesias de San Martiño de Mondoñedo y San Bartolomé de Rebordáns ${ }^{16}$.

En el bloque II hemos estudiado la arquitectura de ambas iglesias. Para hacerlo hemos optado por una organización trifásica en la que inicialmente nos centramos en los

${ }^{15}$ MARTÍNEZ DÍEZ, Gonzalo - Legislación conciliar del Reino Astur (718-910) y del Reino de León (910-1230). León: Centro de Estudios e Investigación San Isidoro, 2009.

${ }^{16}$ Junto con los trabajos generales mencionados en la nota 14, para el estudio pormenorizado de estos dos templos consúltese: BANGO TORVISO, Isidro Gonzalo - Arquitectura románica en Pontevedra. A Coruña: Fundación Pedro Barrié de la Maza, 1979; BANGO TORVISO, Isidro Gonzalo - Galicia Románica. Vigo: Galaxia, 1987; YZQUIERDO PERRÍN, Ramón - De arte et architectura: San Martin de Mondoñedo. Lugo: Diputación Provincial de Lugo, Servicio de Publicaciones, 1994; CASTIÑEIRAS GONZÁLEZ, Manuel Antonio - "La actividad artística en la antigua provincia de Mondoñedo: del Prerrománico al Románico". Estudios mindonienses: Anuario de estudios histórico-teológicos de la diócesis de Mondoñedo-Ferrol 15 (1999), pp. 287-342; CASTIÑEIRAS GONZÁLEZ, Manuel Antonio "San Martiño de Mondoñedo (Foz) Revisitado". in SINGUL LORENZO, Francisco (dir.) - Rudesindus. A terra e o templo. Santiago de Compostela: Dirección Xeral de Turismo-S.A. de Xestión do Plan Xacobeo, 2007, pp. 118-137. 
posibles condicionantes prerrománicos de ambas sedes, para posteriormente concretar aquellas fases fechables en el periodo románico. En medio de ambos conceptos puramente histórico-artísticos hemos querido realizar unas pequeñas reflexiones acerca de las nuevas lecturas que la arqueología de la arquitectura ha proporcionado sobre estas fábricas, con la intención de poder determinar dónde se encuentran las transformaciones entre los "antiguos" conceptos altomedievales y aquellos "novedosos" románicos -si es que tal cambio existió verdaderamente-.

El bloque III es el dedicado al fenómeno de la imagen. En él analizamos en profundidad un total de dieciocho capiteles - siete en Rebordáns y once en Mondoñedo- y una pieza de arte mueble denominada generalmente como "el antipendio de San Martiño de Mondoñedo" (fig. 1). Nuestro enfoque de análisis de los elementos figurativos de ambas empresas artísticas ha sido triple, y hemos querido poner la atención tanto en sus características formales como en su iconografía y, finalmente, en los posibles modelos y arquetipos en los que los maestros ejecutores pudieron haberse inspirado. De ninguna manera esta estructura tripartita se ha planteado como algo cerrado, y en cada caso se ha actuado con relación a aquellos elementos que pudieran ser más significativos. Una excepción paradigmática es el propio antipendio, en el que la reflexión sobre su posible función como objeto litúrgico ha ocupado una extensión que evidentemente no es posible para los capiteles.

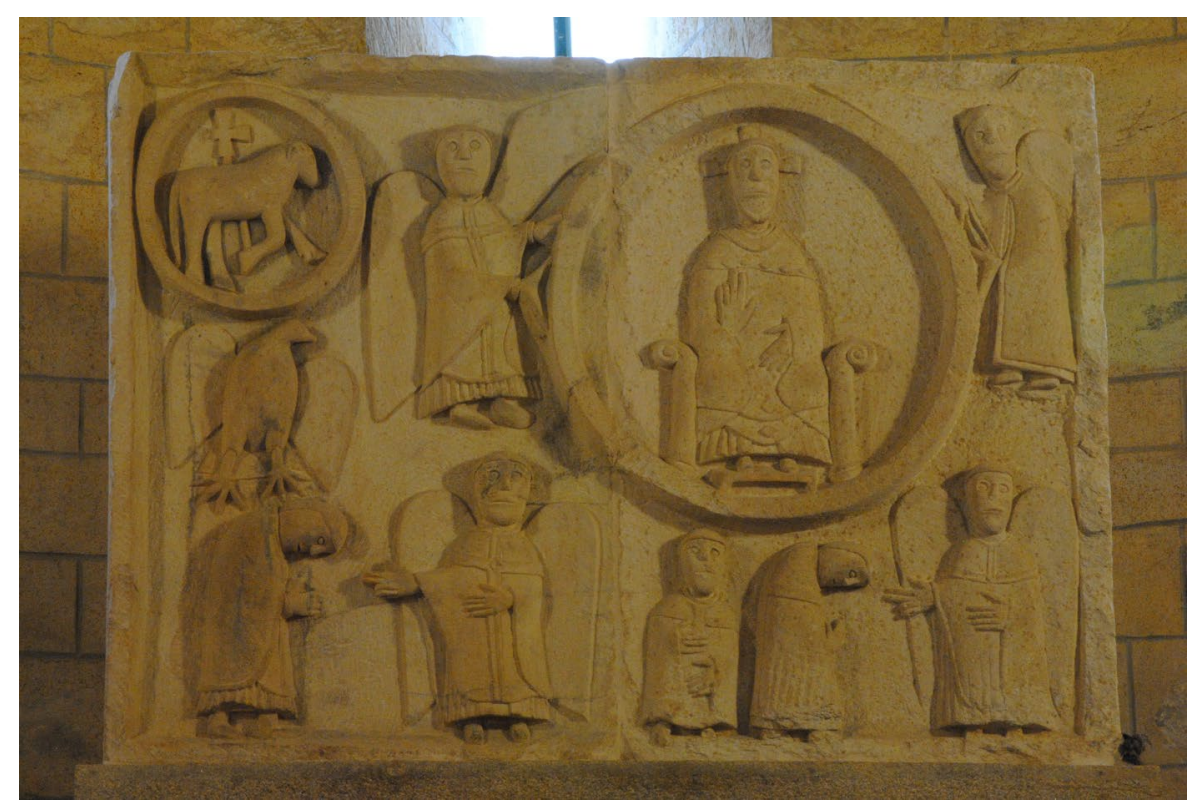

Fig. 1 - Antipendio de Mondoñedo. 
El último de los bloques es el dedicado a los aspectos conclusivos de este trabajo. En él, como hemos dicho, unificamos la lectura de la arquitectura y la escultura en aras de poder medir las afinidades y divergencias entre las sedes objeto de estudio y los preceptos de las reformas cluniacense y romana. En aras de la mayor claridad expositiva hemos dividido este capítulo final en cinco apartados:

1 Resumen en el que realizamos un breve estado de la cuestión acerca de lo expuesto y de la tradición historiográfica "gregoriana" del románico del noroeste ibérico.

2 El papel de los obispos en su condición de posibles promotores artísticos y transmisores de los valores ideológicos de la reforma.

3 La relación de los espacios y las imágenes estudiadas con la liturgia en un momento de transición entre los ritos hispano y romano.

4 Los posibles modelos del primer románico gallego y su vinculación con los valores formales del clasicismo grecorromano.

5 La posición de Compostela con relación a los supuestos valores estéticos gregorianos.

Finalmente, el último de los apartados de este trabajo de investigación se corresponde con una suerte de resumen que, a modo de epílogo, pretende sintetizar las principales temáticas de este.

Antes de pasar a mostrar algunos casos prácticos a modo de ejemplo, quisiéramos insistir en el enfoque metodológico que pretendimos desarrollar en esta tesis doctoral. Partimos de la concepción historiográfica clásica por la que entendemos los años finales del siglo XI como un momento de cambio en el que se precipitan toda una serie de acontecimientos político-religiosos que propiciaron el fin de un conjunto de estructuras heredadas de la Alta Edad Media y, también, la consolidación de un nuevo escenario que, más abierto a Europa, sirvió como pedestal para el desarrollo bajomedieval hispano. Estos preceptos coinciden en lo histórico-artístico con la aparición del nuevo lenguaje monumental románico, lo que en una cierta medida ha propiciado que de manera automática asociemos cambios políticos con cambios culturales. Estas dinámicas han llevado a la creación de toda una corriente historiográfica basada en la 
idea de que las reformas políticas y religiosas - de Cluny y Roma principalmente- son las generadoras de los cambios edilicios y estéticos.

Por ello, gran parte de nuestro trabajo se centra en un análisis crítico de la tradición historiográfica, tanto aquella de corte teórico que ha generado los grandes ejes definitorios del arte románico, como sobre todo de aquella más ceñida al ámbito estricto de las iglesias de San Martiño de Mondoñedo y San Bartolomé de Rebordáns. Partiendo de esta masa crítica, nuestros análisis iconográficos y formales han pretendido dilucidar si estos ejemplos pueden encuadrarse en algunas de las categorías que la mencionada historiografía ha considerado como definitorias de los lenguajes artísticos reformados. Una vez realizados dichos análisis, procedimos a la inversa, tratando de esclarecer si determinadas elecciones formales o temáticas de los templos estudiados pueden ayudar a identificar un panorama político afín a la reforma para estas sedes o si, por el contrario, los discursos espaciales y visuales deben encuadrase más bien dentro de una corriente de reticencias y enfrentamientos contra el nuevo status quo reformista. Dicho de otro modo, si debemos definir el arte románico en sus vínculos con las reformas o, por el contrario, con sus relaciones con toda una serie de persistencias o, incluso, resistencias conscientes.

A continuación, hemos escogido dos ejemplos que consideramos especialmente significativos para el espíritu de este trabajo. En el ámbito de la imagen quisiéramos detenernos en el denominado antipendio de San Martiño de Mondoñedo ${ }^{17}$, mientras que para el estudio de la arquitectura nos centraremos en algunos aspectos de la planimetría de San Bartolomé de Rebordáns. Entendemos, que estos dos ejemplos resultan paradigmáticos de las tendencias artísticas de la Galicia del siglo XI, más allá de las soluciones que estaban aportando los diversos talleres de la catedral de Santiago de Compostela.

17 CASTIÑEIRAS GONZÁLEZ, Manuel Antonio - "San Martiño de Mondoñedo..., pp. 118-137; CASTIÑEIRAS LÓPEZ, Javier - "Imágenes de conflicto: la influencia de los beatos en San Martiño de Mondoñedo". in LOBATO FERNÁNDEZ, Abel; REYES AGUILAR, Esperanza de los; PEREIRA GARCÍA, Irene; GARCÍA GONZÁLEZ, Cristina (ed.) - El legado hispánico: manifestaciones culturales y sus protagonistas. León: Universidad de León, Área de publicaciones, 2016, pp. 251-272. 
El antipendio de Mondoñedo se dispone en la capilla mayor de la iglesia. La pieza tiene unas dimensiones de $115 \mathrm{~cm}$ de largo por $80 \mathrm{~cm}$ de alto. En toda la superficie de la cara frontal se desarrolla un ciclo de imágenes, con un total de diez personajes que se destacan sobre un fondo liso y se enmarcan en sus cuatro caras por medio de un sencillo biselado. Las características formales a la hora de componer dichas figuras son las mismas que las del conjunto de capiteles del crucero, con unas formas esenciales pero de gran expresividad. La pieza presenta una importante grieta que va de arriba abajo en la parte central, a la altura de la mandorla que enmarca a Cristo. Esta fragmentación es la que ha llevado a discutir, junto con la falta de simetría, sobre la ausencia o no de una tercera pieza, aspecto que con prudencia descartamos.

La falta de simetría compositiva entre las figuras es patente, hasta el punto de que no queda nada claro cuál es el orden de la lectura de las imágenes ni dónde empieza o termina la narración del relieve. Por el contrario, sí parece evidente que el relato se divide en dos bloques: el superior con cinco figuras intercaladas que ocupan una superficie que viene dada por la mandorla de Cristo, y que casi ocupa las tres cuartas partes del total del frente de la representación; el registro inferior es, por lo tanto, mucho más reducido y en él cinco nuevas figuras se despliegan a modo de friso corrido.

Las imágenes del registro superior no presentan grandes problemas de identificación y a la derecha encontramos a Cristo entronizado mientras que la izquierda es ocupada por la representación del Agnus Dei. La imagen inferior es ciertamente más problemática y se han planteado diversas hipótesis para su lectura que van desde una ordenación sacerdotal hasta una consagración episcopal o la representación del anuncio a las Siete Iglesias de Asia, entre otras, si bien existe un acuerdo generalizado por el que el tema representado en el relieve toma como fuente el texto del Apocalipsis.

Sin duda, uno de los aspectos que más ha llamado la atención de los diversos investigadores que han analizado la iconografía del antipendio es la rica decoración de los ropajes de las figuras representadas. El uso de albas y casullas, vestimenta habitual del estamento religioso, por parte de todas las figuras del nivel inferior ha llevado a algunos autores a poner en relación esta posible dignificación visual del clero con los ideales reformadores gregorianos. Sin poder descartar esta opción completamente, sí 
quisiéramos hacer notar que, dado el importante peso de las representaciones clericales en la cultura visual hispana altomedieval, ¿no pudieron acaso ser los modelos para el antipendio ejemplos miniados desconocidos similares a los de los códices albeldense o emilianense (ambos altomedievales) donde existe una amplia y rica muestra de imágenes de religiosos suntuosamente ataviados, y no tanto otros ultrapirenaicos vinculados a Roma?

Junto con la importancia de las vestimentas, también ha llamado la atención el marcado arcaísmo formal de las figuras del relieve, hecho que ha sido puesto directamente en relación con el particularísimo mundo de la miniatura desarrollada en las diversas copias de los Beatos, hasta el punto de plantearse la existencia de un Beato galaico hoy perdido (quizá el ejemplar de Celanova) que hubiese servido como fuente al maestro de la pieza. Estos dos aspectos no son únicos de la pieza gallega, y hay una serie de obras más o menos coetáneas en las que se rastrean importantes concomitancias que nos han ayudado a comprender mejor el objeto estudiado. Nos referimos al sepulcro de San Martín de Dumio, a la lauda de Alfonso Ansúrez de Sahagún, a la pila bautismal de San Isidoro de León o al tímpano de la abadía aquitana de Saint-Sever en Landes ${ }^{18}$.

En conclusión, y de manera somera, consideramos que nos encontramos ante una pieza de exaltación sacerdotal cuyo significado se relaciona además con el discurso admonitorio de la serie de capiteles del templo, completando así un conjunto figurativo que entendemos que no tiene por qué vincularse estrictamente con las novedades gregorianas, sino que, más bien, en él son fuertes los vínculos formales y temáticos con la cultura autóctona precedente. Esta cuestión nos ha hecho plantearnos si podríamos estar ante un ciclo figurativo propio de la liturgia hispana y, quizá, contrario a la reforma, pero ante esta afirmación debemos mostrarnos cautos ya que es mucho aún lo

\footnotetext{
${ }^{18}$ MIGUÉLEZ CAVERO, Alicia - "La impaginatio como punto de partida: la relación entre texto e imagen en la cubierta del sarcófago de Alfónso Pérez procedente de Sahagún". in GARCÍA LOBO, Vicente; MARTÍN LÓPEZ, M. Encarnación (coord.) - Impaginatio en las inscripciones medievales. León: Universidad de León, Área de publicaciones, 2011, pp. 71-97; MORENO MARTÍN, Francisco José - "El sarcófago de Dumio en el contexto de la Reforma Gregoriana". in VARELA FERNÁNDEZ, Carla (coord.) - Imagens e Liturgia na Idade Média. Moscavide: Secretariado Nacional para os Bens Culturais da Igreja, 2016, pp. 179-210; CABANOT, Jean - "Le tympan du portail nord de Saint-Sever (Landes): Le Beatus et le décor sculpté de l'abbatiale". in GALLET, Yves (ed.) - Ex quadris lapidibus. La pierre et sa mise en oeuvre dans l'art médiéval, Mélanges d'Histoire de l'art offerts à Éliane Vergnolle. Turnhout; Brepols, 2012, pp. 389-402.
} 
que desconocemos y mucho también lo perdido. Pero, en cualquier caso, en esta ocasión apostamos por una mayor impronta del sustrato cultural hispano que de las nuevas corrientes europeas.

El segundo de los ejemplos en los que nos quisiéramos detener es la iglesia de San Bartolomé de Rebordáns (fig. 2), que se encuentra en la población pontevedresa de Tui. Se trata del único vestigio de un antiguo conjunto monástico que, en la cronología que nos ocupa, también ostentó temporalmente la condición de sede episcopal. En su visión actual exterior, el edificio acusa abundantes modificaciones con respecto a la fábrica románica, pero tanto el interior como la articulación de volúmenes y la planimetría responden en gran medida a la iglesia del siglo XI.

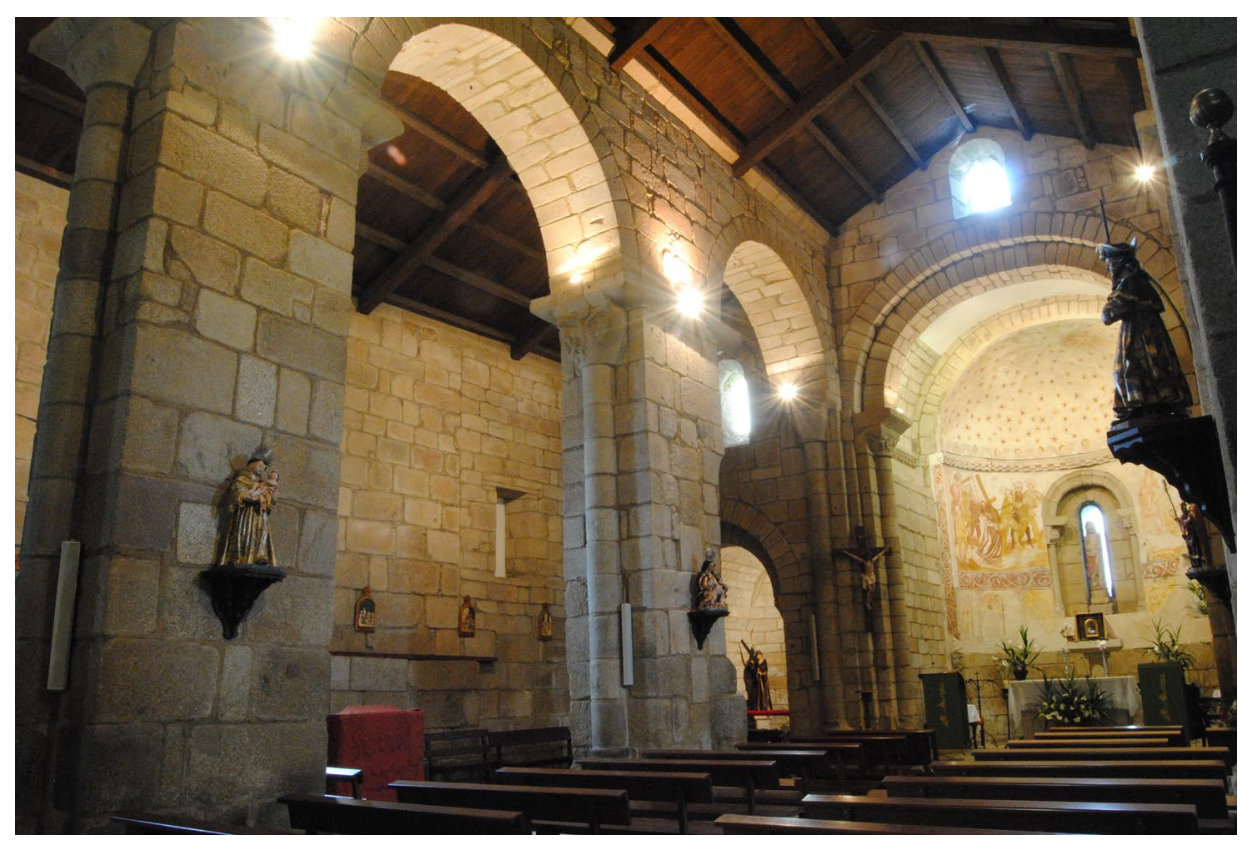

Fig. 2 - San Bartolomé de Rebordáns.

San Bartolomé es un edificio de tres naves y tres ábsides, con testero recto en los laterales y semicircular en el central, si bien este perfil se corresponde con una fase de obras posterior, ya del siglo XII. Uno de los aspectos más interesantes de la planimetría de Rebordáns es la posibilidad de la existencia, a tenor de la documentación, de una serie de capillas adosadas a las naves laterales que dibujarían un falso transepto. Este supuesto fue constatado en el año 2016 en una breve, pero muy interesante, campaña de excavaciones arqueológicas que sacó a la luz los cimientos de una de ellas. Estructuras de estas características se encuentran en numerosas iglesias de la Alta Edad Media 
peninsular como Quintanilla de las Viñas, San Pedro de la Nave o la gallega Santa Comba de Bande ${ }^{19}$. Es demasiado lo que desconocemos sobre estos espacios en la iglesia de San Bartolomé de Rebordáns para elucubrar acerca de un posible uso, ya sea este como cámara penitencial o como sacristía, tesoro, etc., pero sí creemos que su presencia se puede relacionar espacial y planimétricamente con modelos prerrománicos. De cualquier modo, las cámaras laterales y la cabecera triple con testero recto en fechas ya románicas, nos llevan a definir a esta construcción como retardataria y como parte de una arquitectura de transición con un vínculo todavía muy estrecho con concepciones espaciales altomedievales (pero ya en cronología románica). Esta dinámica, por la que construcciones de cronología románica optan por soluciones conservadoras, puede atestiguarse también en algunos otros ejemplos significativos del paisaje monumental del noroeste como en la iglesia de San Juan y San Pelayo (posterior San Isidoro) en León o San Pedro de Teverga en el sur de Asturias ${ }^{20}$.

Por lo tanto, parece que el modo de concebir el espacio en Rebordáns es todavía deudor de los conceptos prerrománicos $\mathrm{y}$, quizá, las tradicionalmente invocadas fábricas precedentes no definan estas realidades, sino que estos atavismos sean elecciones conscientes y que el conjunto de la fábrica tudense sea de nueva construcción y no tanto un edificio altomedieval remozado en el último tercio del siglo XI.

Románica o no, la iglesia de San Bartolomé de Rebordáns responde a planteamientos arquitectónicos alejados de lo que en las mismas cronologías se estaba ensayando en los grandes centros "revolucionarios" del románico europeo. Por ello posiblemente los términos "prerrománico" o "románico", hijos de una cerrada historia artística de los estilos, no resulten satisfactorios para definir estos espacios que se desarrollan como bisagras entre dos lenguajes edilicios diferentes.

19 CARRERO SANTAMARÍA, Eduardo; RICO, Daniel - "La organización del espacio litúrgico hispánico entre los siglos VI y XI". Antiquité Tardive. Revue Internationale d'Histoire et d'Archéologie (IVe-VIIe siècle) 23 (2015), pp. 239-248.

${ }^{20}$ ALONSO ÁLVAREZ, Raquel - "La colegiata de San Pedro de Teverga. La 'imagen medieval' de un edificio reformado". Asturiensia Medievalia 7 (1993-1994), pp. 225-242; FERNÁNDEZ GONZÁLEZ, Etelvina - "Reflexiones sobre la evolución hacia el románico de las fórmulas artísticas altomedievales, en el ámbito astur-leonés, de la undécima centuria", in ARBEITER, Achim (coord.) - Hispaniens Norden im 11. Jahrhundert. Christliche Kunst im Umbruch / El norte hispánico en el siglo XI. Un cambio radical en el arte cristiano. Göttingen: Petersberg, 2009, pp. 48-72. 
Iniciábamos este estudio sobre el arte románico del territorio de gallego en el siglo XI planteándonos la directa pregunta: ¿es el románico de Galicia un arte de la reforma?

Para tratar de proporcionar algo de luz a esta cuestión, nos pareció fundamental entender el contexto sociopolítico en el que se desarrollaron el románico y la reforma gregoriana. Como hemos visto, esta cristalizó en el occidente peninsular por medio de la mediación de los legados papales y de una serie de monjes de la abadía de Cluny que, paulatinamente, fueron ocupando ciertas posiciones de poder-como el arzobispo Bernardo de Toledo-. Las ideas defendidas por estos religiosos renovadores fueron puestas en común con el resto del alto clero hispano en una serie de concilios, entre los que destaca el de Burgos de 1080, por su peso histórico, al haberse tomado en él la decisión de suprimir el antiguo rito litúrgico hispano. De la mano de esta actividad conciliar, se produjo una profunda reorganización eclesiástica que afectó especialmente al territorio de Galicia por medio de la restitución en 1071 del obispado de Braga posterior arzobispado- y por el traslado de iure de la dignidad episcopal desde Iria a Compostela en $1095^{21}$.

En paralelo a esta política proveniente del exterior peninsular se produjeron toda una serie de hechos que vinieron sin embargo a reforzar conceptos netamente hispanos -la llegada de los restos de san Isidoro a León en 1063 y la toma de Toledo en 1085-que generaron una suerte de neovisigotismo cultural y político del que era partícipe una monarquía que, especialmente en tiempos de Alfonso VI, realizó un destacado equilibrio político entre los aires renovadores y la independencia de su potestas.

Una vez que planteamos sucintamente las dinámicas políticas en las que se enmarcaban las campañas artísticas a estudiar, entendimos que antes de iniciar nuestro análisis resultaba conveniente una exposición crítica de la corriente historiográfica en la que consideramos se inspira nuestra tesis doctoral. La idea del arte y la reforma "nace" con los trabajos de W. Weisbach sobre Cluny y de E. Kitzinger sobre Roma, si bien su gran desarrollo se produce a partir de los estudios de H. Toubert y A. C. Quintavalle. Estos y

\footnotetext{
21 La bibliografía científica sobre estos procesos históricos es inabordable en este trabajo por ello remitimos de nuevo a la lectura del trabajo completo donde se detalla la copiosa tradición historiográfica sobre estos aspectos.
} 
otros historiadores e historiadores del arte han definido una gran parte del arte románico desde la premisa de que este nace como una respuesta cultural a los nuevos planteamientos religiosos y políticos dados en llamar "reforma gregoriana".

Nuestra pregunta de si estas afirmaciones son aplicables al caso gallego no es pionera en este estudio, y algunos autores que nos preceden le han dado ya respuesta, especialmente y como ya se ha señalado, en la aplicación del método al caso compostelano. Para ellos, y con los que coincidimos en gran medida, en Santiago se produce una ruptura, un cambio en los criterios estéticos y monumentales con respecto al pasado altomedieval hispano que, quizá tengan en los grandes portales del periodo gelmiriano su máxima expresión. La respuesta estaba dada: Compostela es un paladín de la reforma. Pero ¿lo es todo el primer románico de Galicia? Con la intención de dar respuesta a esta cuestión - $\mathrm{o}$ al menos intentarlo- centramos nuestro análisis en los dos centros episcopales (ambos efímeros), al margen de la catedral de Santiago, que conservan un mayor número de vestigios del periodo. Seguidamente hemos procedido al estudio por separado de los discursos figurativos de ambas iglesias y de sus estructuras arquitectónicas.

Una vez analizados los conjuntos figurativos y la arquitectura de las dos construcciones a estudiar, consideramos que ambas iglesias basculan entre conceptos altomedievales y románicos que dificultan en demasía su encaje en las teorías gregorianas. En nuestra opinión, de entre los elementos conservadores hay dos muy significativos: una parte de los motivos iconográficos se relacionan -textual y visualmente- con libros litúrgicos hispánicos, en un momento de supresión de esta liturgia auspiciado por Roma; y, además, no existe un diálogo entre estos ciclos esculpidos y el referente visual clásico, que, como hemos visto, es una de las principales dinámicas de la cultura visual gregoriana. Asimismo, hemos apuntado hacia como el papel de patronazgo de los obispos no puede enmarcarse indiscutiblemente en los conceptos de la reforma e, incluso, resulta posible que estos prelados gallegos fuesen parte de una corriente reticente a los cambios reformadores.

Ante lo expuesto, quisiéramos recuperar la pregunta con la que iniciábamos nuestro estudio: ¿son las campañas artísticas de San Martiño de Mondoñedo y San Bartolomé 
de Rebordáns un ejemplo de lo que se ha venido dando en llamar un "arte reformado" o, por el contrario, estamos ante muestras de una cultura conservadora y refractaria a los cambios?

La respuesta que podemos dar tras nuestra investigación es la siguiente: los espacios y las imágenes de San Martiño de Mondoñedo y San Bartolomé de Rebordáns son explicables en un momento de transición entre la cultura altomedieval hispana y el incipiente lenguaje románico. En ambas iglesias existe un porcentaje lo suficientemente elevado de elementos vinculados con la tradición anterior que hacen casi imposible que hablemos de discursos artísticos de la reforma gregoriana. Esto, en cualquier caso, no prueba que ambas sedes sean contrarias a la reforma y partidarias de la causa indigenista, pero sí vienen a mostrar la convivencia de lenguajes arquitectónicos y figurativos en una Galicia a finales del siglo XI que, en nuestra opinión, podría definirse como una cultura artística de transición.

En definitiva, las primitivas sedes de los obispados de Mondoñedo y Tui perdieron su condición, y sus campañas artísticas ejercieron una nula influencia posterior. De este modo, cuando en 1112 se derrumbaba el segundo santuario compostelano, llegaba a Mondoñedo un nuevo obispo partidario de la reforma -amparado por el mismísimo Gelmírez- y en ambas sedes, así como en el conjunto de Galicia, terminaba un modo de entender las artes propio del periodo altomedieval y comenzaba a triunfar un románico europeo que tuvo, en estas latitudes, su más sobresaliente expresión en los "gregorianos" portales de la catedral de Santiago de Compostela.

En síntesis creemos que las campañas artísticas de Mondoñedo y Rebordáns no encajan en la categoría de un arte de la reforma gregoriana siendo sin embargo, tanto por cronología como por ciertos aspectos de forma, obras románicas de pleno derecho. Por ello, entendemos que en el noroeste peninsular de finales del siglo XI se producen unos discursos artísticos que, lejos de ser uniformes, se caracterizan por un complicado equilibrio entre las persistencias culturales y las reformas religioso-políticas. Sin duda, es esta una línea de trabajo absolutamente abierta que podrá ser retomada en un futuro inmediato, posiblemente reiniciando el estudio a partir de la huella (solo esbozada en esta tesis) que las obras no medievales han dejado en dichas sedes y que pudieron, a 
buen seguro, habernos legado un imaginario "pseudomedieval" muy diferente al que conoció el siglo XI.

\section{Referências bibliográficas:}

ALONSO ÁlVAREZ, Raquel - "La colegiata de San Pedro de Teverga. La 'imagen medieval' de un edificio reformado". Asturiensia Medievalia 7 (1993-1994), pp. 225242.

BANGO TORVISO, Isidro Gonzalo - Arquitectura románica en Pontevedra. A Coruña: Fundación Pedro Barrié de la Maza, 1979.

BANGO TORVISO, Isidro Gonzalo - Galicia Románica. Vigo: Galaxia, 1987.

BARRAL I ALTET, Xavier - Contre l'art roman? Essai sur un passé réinventé. Paris: Fayard, 2006.

CABANOT, Jean - "Le tympan du portail nord de Saint-Sever (Landes): Le Beatus et le décor sculpté de 1'abbatiale". in GALLET, Yves (ed.) - Ex quadris lapidibus. La pierre et sa mise en oeuvre dans l'art médiéval, Mélanges d'Histoire de l'art offerts à Éliane Vergnolle. Turnhout: Brepols, 2012, pp. 389-402.

CARRERO SANTAMARÍA, Eduardo; RICO, Daniel - "La organización del espacio litúrgico hispánico entre los siglos VI y XI". Antiquité Tardive. Revue Internationale d'Histoire et d'Archéologie (IVe-VIIe siècle) 23 (2015), pp. 239-248.

CASTIÑEIRAS GONZÁLEZ, Manuel Antonio - "La actividad artística en la antigua provincia de Mondoñedo: del Prerrománico al Románico”. Estudios mindonienses: Anuario de estudios histórico-teológicos de la diócesis de Mondoñedo-Ferrol 15 (1999), pp. 287-342. 
CASTIÑEIRAS GONZÁLEZ, Manuel Antonio - "San Martiño de Mondoñedo (Foz) Revisitado". in SINGUL LORENZO, Francisco (dir.) - Rudesindus. A terra e o templo. Santiago de Compostela: Dirección Xeral de Turismo-S.A. de Xestión do Plan Xacobeo, 2007, pp. 118-137.

CASTIÑEIRAS GONZÁLEZ, Manuel Antonio - "Didacus Gelmirius, patrono de las artes. El largo camino de Compostela: de periferia a centro del Románico". in CASTIÑEIRAS GONZÁLEZ, Manuel Antonio - Compostela y Europa. La historia de Diego Gelmírez. Santiago de Compostela-Milán: Skira/S. A. de Xestión do Plan Xacobeo, 2010, pp. 32-97.

CASTIÑEIRAS LÓPEZ, Javier - "Imágenes de conflicto: la influencia de los beatos en San Martiño de Mondoñedo”. in LOBATO FERNÁNDEZ, Abel; REYES AGUILAR, Esperanza de los; PEREIRA GARCÍA, Irene; GARCÍA GONZÁLEZ, Cristina (ed.) El legado hispánico: manifestaciones culturales y sus protagonistas. León: Universidad de León, Área de publicaciones, 2016, pp. 251-272.

CASTIÑEIRAS LÓPEZ, Javier - Espacios e Imágenes en el reino de Galicia (10751112). Persistencias y reforma. Tesis Doctoral Inédita, Universidade de Santiago de Compostela: 2018.

FERNÁNDEZ GONZÁLEZ, Etelvina - "Reflexiones sobre la evolución hacia el románico de las fórmulas artísticas altomedievales, en el ámbito astur-leonés, de la undécima centuria". in ARBEITER, Achim (coord.) - Hispaniens Norden im 11. Jahrhundert. Christliche Kunst im Umbruch / El norte hispánico en el siglo XI. Un cambio radical en el arte cristiano. Göttingen: Petersberg, 2009, pp. 48-72.

FLITCHE, Augustine - La Réforme Grégorienne. 3 vol. Genève: Slatkine Reprints, 1978 [1924-1937].

FRANZÉ, Barbara (dir.) - Art et reforme grégorienne (XIe-XIIe siècles) en France et dans la péninsule Ibérique, Paris: Éditions A. et J. Picard, 2015. 
GARCÍA GARCÍA. Francisco de Asís - Los portales de la catedral de Jaca. Reforma eclesiástica y poder real a finales del siglo XI. Huesca: Instituto de Estudios Altoaragoneses (Diputación de Huesca), 2018.

GARCÍA GUINEA, Miguel Ángel, et alii (dir.) - Enciclopedia del Románico en Galicia. Aguilar de Campoo: Santa María la Real Fundación, 2012-2018.

GUGGENHEIM, Sylvain - La Réforme Grégorienne. De la lutte pour le sacré à la secularisation du monde. Paris: Temps Présent, 2010.

KESSLER, Herbert Leon - “A Gregorian Reform Theory of Art?”. in ROMANO S.;

ENCKELL J. (ed.) - Roma e la Riforma gregoriana: tradizioni e innovazioni artistiche (XI-XII secolo). Roma: I libri di Viella, 2007, pp. 25-48.

KITZINGER, Ernst - "The Gregorian Reform and the visual arts: a problem of method". Transactions of the Royal Historical Society, vol. 22 (1972), pp. 87-102.

MARTÍNEZ DÍEZ, Gonzalo - Legislación conciliar del Reino Astur (718-910) y del Reino de León (910-1230). León: Centro de Estudios e Investigación San Isidoro, 2009.

MIGUÉLEZ CAVERO, Alicia - "La impaginatio como punto de partida: la relación entre texto e imagen en la cubierta del sarcófago de Alfónso Pérez procedente de Sahagún”. in GARCÍA LOBO, Vicente; MARTÍN LÓPEZ, M. Encarnación (coord.) Impaginatio en las inscripciones medievales. León: Universidad de León, Área de publicaciones, 2011, pp. 71-97.

MORENO MARTÍN, Francisco José - "El sarcófago de Dumio en el contexto de la Reforma Gregoriana". in VARELA FERNÁNDEZ, Carla (coord.) - Imagens e Liturgia na Idade Média. Moscavide: Secretariado Nacional para os Bens Culturais da Igreja, 2016, pp. 179-210.

PACE, Valentino - "Roma e la Riforma gregoriana. Tradizioni e innovazioni artistiche (XI-XII secolo)". in ROMANO Serena; ENCKELL Julie (ed.) - Roma e la Riforma 
gregoriana: tradizioni e innovazioni artistiche (XI-XII secolo). Roma: I libri di Viella, 2007, pp. 49-59.

REILLY, Bernard - El Reino de León y Castilla bajo el Rey Alfonso VI: 1065-1109. Toledo: Instituto Provincial de Investigaciones y Estudios Toledanos, 1989.

ROMANO, Serena; ENCKELL, Julie (ed.) - Roma e la Riforma gregoriana: tradizioni e innovazioni artistiche (XI-XII secolo). Roma: I libri di Viella, 2007.

TELLENBACH, Gerd - Church, State and Christian Society at the time of the Investiture Contest. Oxford: Basil Blackwell, 1966 [1959].

TOUBERT, Hélène - Un art dirigé. Réforme grégorienne et Iconographie. Paris: Editions du Cerf, 1990.

WEISBACH, Werner - Religiöse Reform und mittelalterliche Kunst. Einsiedeln-Zürich: Verlagsanstalt Benziger and Co., 1945.

YZQUIERDO PERRÍN, Ramón - Galicia. Arte Medieval (I), tomo X. A Coruña: Hércules, D. L., 1993.

YZQUIERDO PERRÍN, Ramón - De arte et architectura: San Martin de Mondoñedo. Lugo: Diputación Provincial de Lugo, Servicio de Publicaciones, 1994. 
Espacios e Imágenes en el reino de Galicia (1075-III2). Persistencias y reforma • Javier Castiñeiras López

\section{COMO CITAR ESTE ARTIGO}

\section{Referência electrónica:}

CASTIÑEIRAS LÓPEZ, Javier - "Espacios e Imágenes en el reino de Galicia (10751112). Persistencias y reforma”. Medievalista 26 (Julho-Dezembro 2019). [Em linha] [Consultado dd.mm.aaaa]. Disponível em http://www2.fcsh.unl.pt/iem/medievalista/MEDIEVALISTA26/lopez2612.html ISSN 1646-740X.

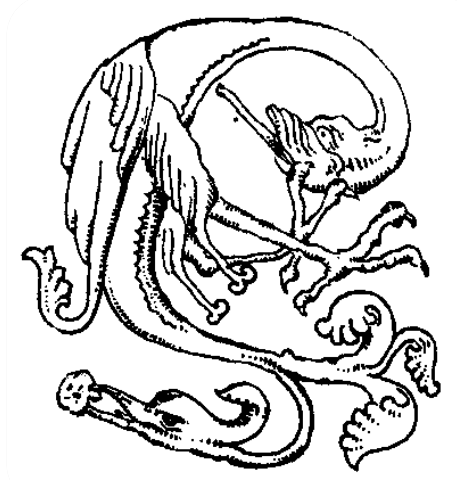

